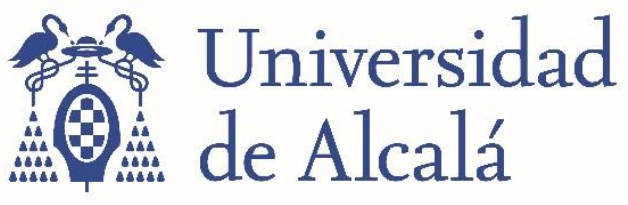

BIBLIOTECA

Document downloaded from the institutional repository of the University of Alcala: http://dspace.uah.es/dspace/

This is the peer reviewed version of the following article:

Castro-Díez, P., Pauchard, A., Traveset, A., Vilà, M. \& Kühn, I. 2016, "Linking the impacts of plant invasion on community functional structure and ecosystem properties", Journal of Vegetation Science, vol. 27, no. 6, pp. 1233-1242.

Which has been published in final form at

Available at http://dx.doi.org/10.1111/jvs.12429

This article may be used for non-commercial purposes in accordance with Wiley Terms and Conditions for Use of Self-Archived Versions.

(C) 2016 John Wiley \& Sons
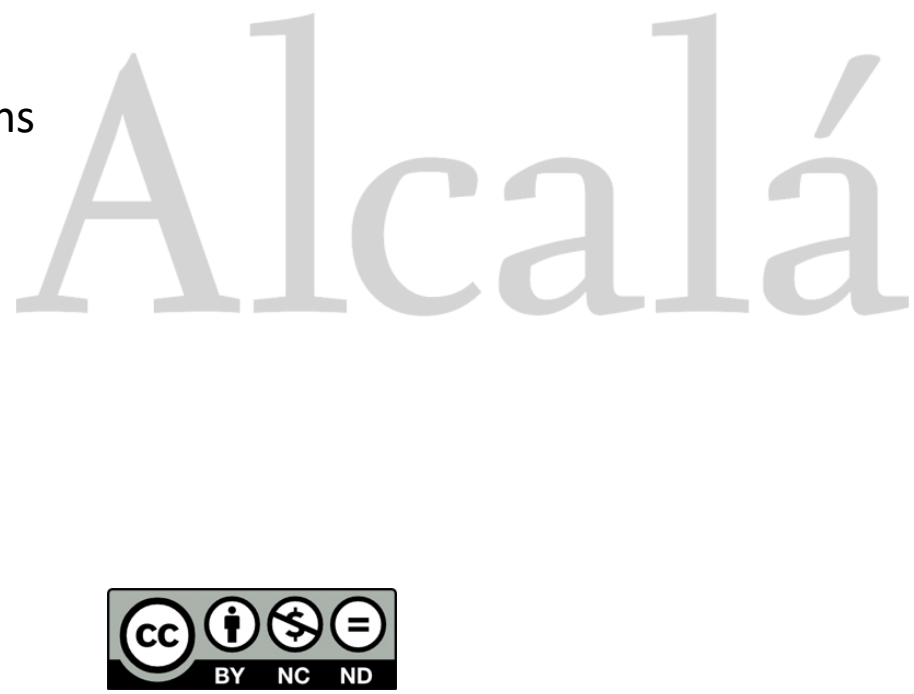

This work is licensed under a

Creative Commons Attribution-NonCommercial-NoDerivatives

4.0 International License. 


\title{
Linking the impacts of plant invasion on community functional structure and ecosystem properties
}

\author{
Pilar Castro-Díez, Aníbal Pauchard, Anna Traveset \& Montserrat Vilà
}

Castro-Díez, P. (corresponding author, mpilar.castro@uah.es) ${ }^{1}$

Pauchard, A. (pauchard@udec.cl)2,3

Traveset, A. (atraveset@imedea.uib-csic.es) ${ }^{4}$

Vilà, M. (montse.vila@ebd.csic.es) $)^{5}$

\author{
${ }^{1}$ Departamento de Ciencias de la Vida Facultad de Biología, Universidad de Alcalá. Carretera \\ Madrid-Barcelona, Km 33.6, 28871, Alcalá de Henares, Madrid, Spain \\ ${ }^{2}$ Facultad de Ciencias Forestales, Universidad de Concepción, Casilla 160-C, Concepción, Chile \\ ${ }^{3}$ Institute of Ecology and Biodiversity (IEB), Chile \\ ${ }^{4}$ Instituto Mediterráneo de Estudios Avanzados, Grupo de Investigación en Cambio Global, \\ IMEDEA (CSIC-IUB), ES-07190 Esporles, Mallorca, Islas Baleares, Spain \\ ${ }^{5}$ Estación Biológica de Doñana (EBD-CSIC), Avda. Américo Vespucio s/n. Isla de la Cartuja, \\ 41092 Sevilla, Spain
}

Nomenclature:

Running head: Invasion and community functional structure

\begin{abstract}
Questions: Many studies report a decrease of native species richness in communities after plant invasion by exotic taxa, but the implications of species losses on community functional structure and ecosystem processes have been less explored. The questions addressed are: What are the impacts of invasive plant taxa on the functional structure of the recipient community? Are there links between such functional structure and ecosystem properties standing for key ecosystem processes?

Location: Costal habitats of Mallorca and Menorca (Balearic Islands, Western Mediterranean Sea, Spain) partially invaded by Carpobrotus spp.

Methods: In paired invaded and non-invaded plots, species frequencies and ecosystem properties related to biogeochemical cycles (soil carbon and nitrogen content, soil moisture and decomposition rate) were assessed. For every native species we obtained values of several functional traits (plant height, woodiness, $\mathrm{N}$-fixation and evergreeness). Then we calculated indexes of community functional structure (community weighted means for each trait, functional diversity (richness, evenness, divergence and dispersion) and functional redundancy) and compared them between paired invaded and non-invaded plots. The relation with ecosystem properties was assessed by using general linear models.

Results: The spectra of trait distribution changed in the invaded assemblages towards a higher frequency of woodiness and evergreeness. Invaded communities showed decreased species richness, and lower functional richness, divergence, dispersion and redundancy. By contrast, ecosystem properties were scarcely sensitive to invasion. Functional redundancy was negatively related to soil nitrogen of invaded plots and soil moisture in the dry season, which
\end{abstract}


suggests a higher depletion of soil resources when several species share the same combination of trait values.

Conclusions: Carpobrotus invasion led to a functional homogenization within communities, which probably reduces their resilience. The functional structure of the community was more responsive to invasion than the ecosystem properties. The weak relationship between functional indexes and ecosystem properties suggests that they may respond to invasion at different rates.

Key-words: biological invasions; Carpobrotus; functional diversity indexes; functional redundancy; Mediterranean communities; non-native plants; plant traits; soil moisture; soil nitrogen; species richness 


\section{Introduction}

Invasive plant species are non-native species which, once arrived to a new region, are able to establish self-sustained populations and spread at a fast rate from the introduction point, (Richardson et al. 2000). Many invasive species cause ecological impacts in the area of introduction. The ecological impact of invasive species is usually assessed by comparing species fitness, community structure or ecosystem processes between invaded and reference non-invaded sites (Gaertner et al. 2009; Vilà et al. 2011; Pyšek et al. 2012; Castro-Díez et al. 2014; Kumschick et al. 2015). One of the most widely-used indicators of the ecological impact is native species richness or diversity, which tends to decrease in invaded sites (Gaertner et al. 2009; Hejda et al. 2009; Vilà et al. 2015). The impact of invasive plant species has also been evaluated by comparing indicators of ecosystem processes, mainly nutrient pools and fluxes (Vilà et al. 2011; Castro-Díez et al. 2014). However, the link between changes in species diversity and changes in ecosystem processes is not straightforward (Hooper \& Vitousek 1997; Tilman et al. 1997).

There is a growing consensus that the effects of diversity on ecosystem processes depend on the functions performed by the different species, rather than on species number per se (Díaz \& Cabido 2001; Cadotte et al. 2011; Hejda \& de Bello 2013). This means that the loss of the same number of species may have different impacts on the ecosystem processes depending on how relevant and/or redundant is the function performed by the lost species (Chapin et al. 1997; Hooper et al. 2005; Oliver et al. 2015). Moreover, the impact of an introduced species to an ecosystem partly depends on how novel the function of this new species is in the invaded community (Chapin et al. 1996; D'Antonio \& Corbin 2003; Thuiller et al. 2010; Castro-Díez et al. 2014).

The use of the functional structure of the community as an indicator of invasion impact may help to bridge the gap between impacts on species diversity and impacts on ecosystem processes. The functional structure of the community is the composition and distribution of functional groups, that is, groups of species sharing similar values of traits (Díaz \& Cabido 2001; Cadotte et al. 2011; Hejda \& de Bello 2013; Finegan et al. 2015). This approach assumes that ecosystem processes are largely determined by certain attributes or "effect traits" of the species in the community (Grime 1998; Díaz \& Cabido 2001; Lavorel \& Garnier 2002). There is a large array of indexes to account for different aspects of functional structure (Laliberte \& Legendre 2010; Casanoves et al. 2011). First, the community weighted mean (CWM) of a single trait is the mean value of that trait across species weighted by their abundances (Garnier et al. 2004; Violle et al. 2007). CWMs are expected to determine some properties and processes of the ecosystems. For instance, CWM of leaf, wood, root or whole-plant traits, have been found to correlate to primary production, litter decomposition or soil $\mathrm{C}$ and $\mathrm{N}$ contents, respectively (Garnier et al. 2004; Butterfield \& Suding 2013; Finegan et al. 2015). Therefore, changes in CWMs due to the invasion of non-native plants are expected to alter ecosystem functioning. Second, the functional diversity of a community (i.e. the variety of trait values in a community and how they are distributed) has been related to the efficiency of resource use in plant communities by the niche complementarity hypothesis (Díaz \& Cabido 2001; Filella \& Peñuelas 2003; Finegan et al. 2015). There are three main multi-trait indexes which capture different aspects of functional diversity (Villeger et al. 2008): functional richness (FRic) is the amount of functional space filled by the community, an analogue of a trait range in a multidimensional space; functional evenness (FEve) is the evenness of abundance distribution in a functional trait space, and functional divergence (FDiv) represents how abundance is spread throughout the functional space of the community. In addition, functional dispersion (FDis) is the mean distance of individual species to the centroid of all species in the multidimensional space defined by species traits, accounting for their abundances (Laliberte \& Legendre 2010). Plant invasions may alter the distribution of traits related to resource use, and therefore change resource availability in the invaded ecosystem. Third, functional redundancy (FRedu) of a 
community is proportional to the number of species representing the same function or combination of trait values. Communities with higher FRedu are considered to be more resilient, as they have less chance of losing a relevant function upon the loss of one species (Mouillot et al. 2013; Oliver et al. 2015). Plant invasions may alter FRedu in either direction, depending on the functional traits of the native species that are more vulnerable to be displaced, and on whether the invader's traits are redundant or not to the traits of the recipient community.

In spite of the advances to quantify the functional structure of the community, and the growing evidences of its relevance on ecosystem processes, little effort has been done to assess the impacts of non-native plants on the functional structure of the invaded community (Hejda \& de Bello 2013), and even less to link these impacts with changes in ecosystem properties (Constan-Nava et al. 2015). We aim to fill these gaps by comparing indexes of functional structure between invaded and non-invaded communities by Carpobrotus spp. N.E. $\mathrm{Br}$. in the Balearic Islands (Spain, Western Mediterranean Sea). Moreover, several ecosystem properties that can be related to key ecosystem processes -specifically nutrient and water cycling- were assessed to test for their relationship with the functional structure. Specifically, we address the following questions: 1) How does the invasion by Carpobrotus spp. modify the CWMs of several selected traits, FRic, FEve, FDiv, FDis and FRedu? 2) Are functional structure indexes related to ecosystem properties? Is this relation altered by the invasion?

Our hypothesis are: 1) Plant invasion modify CWMs, decrease all indexes of functional diversity and functional redundancy, given that Carpobrotus spp. tends to become dominant in the community due to its prolific mat-forming clonal growth (Sintes et al. 2007; Roiloa et al. 2010). 2) CWMs correlate with the ecosystem properties that are more directly linked to the selected traits. 3) According to the niche complementary hypothesis, communities with higher functional diversity take up more soil resources and thus reduce their availability in the soil. 4) Relationships between functional indexes and ecosystem properties are stronger in noninvaded than in invaded sites, because in the later changes in the community may have not yet reached an equilibrium with the soil properties.

\section{Material and Methods}

\section{Field sampling and ecosystem properties}

We used data collected in Mallorca and Menorca, the two largest Balearic Islands (Spain, Western Mediterranean Sea) during spring 2002. Both islands have been invaded by the SouthAfrican succulent clonal chamaephytes Carpobrotus acinaciformis (L.) Bolus and C. edulis (L.) N.E. Br. These species were introduced as ornamentals and for erosion prevention and now they and their hybrids are widely naturalized on coastal rocks, cliffs and sand dunes (Vilà et al. 2006; Traveset et al. 2008a; Traveset et al. 2008b). Given that both species are not always distinguished and share all the functional traits selected in this study (see below), they were considered as a single invasive taxa, namely Carpobrotus.

For each island a set of 21 (Mallorca) and 14 (Menorca) sites were selected across the islands to encompass all coastal habitat types and soil types where Carpobrotus was established. Sites were separated by at least $1 \mathrm{~km}$. In each site, two paired invaded and noninvaded $2 \times 2 \mathrm{~m}$ plots was established, giving a total 35 paired plots. Non-invaded plots were chosen in close vicinity to the invaded ones with the aim of having environmental conditions as similar as possible (Vilà et al. 2006). In each plot, all species were recorded and their frequency was assessed as the number of $50 \times 50 \mathrm{~cm}$ grids where they were present. The average Carpobrotus frequency in invaded plots was 99.4 and 93.3\% in Mallorca and Menorca, respectively.

Several ecosystem properties related to nutrient and water cycles were assessed in each plot, i.e. soil organic carbon, soil total nitrogen, soil C/N ratio (see details in Vilà et al. (2006) 
and Traveset et al. (2008a)). In addition, in a randomly chosen subset of the plots, we estimated soil moisture in the dry (June) and in the wet (October) season, and decomposition rate. Soil moisture was measured by a Time-Domain Reflectometry (TDR) sampling at $7 \mathrm{~cm}$ soil depth next to the plots three times per season on non-rainy days. Decomposition was estimated by the loss of weight of three toothpicks placed on a $1 \mathrm{~mm}$ mesh bag below the litter next to the sampling plot from March to September. Toothpicks have been used as standardized material, mimicking the size of plant stems in the litter, to calculate the decomposition capacity of the soil community.

\section{Plant trait selection and analyses}

The values of the functional indexes are inherently dependent on the traits used to calculate them. Therefore, trait selection is a critical step that should adjust to some criteria (Petchey \& Gaston 2006; Villeger et al. 2008): traits must relate with plant functions relevant to the aim of the study and they should avoid trivial correlations among each other (Petchey \& Gaston 2006; Villeger et al. 2008). In this study we reviewed the literature for traits relevant to nutrient and water cycles. Given the high number of species (189 in total), which were not covered by most datasets of traits, we selected four traits available in on-line national or regional Floras (Flora Iberica (www.floraiberica.es), Flora de Andalucía Occidental (www.floravascular.com), Flora del Mediterráneo Occidental (herbarivirtual.uib.es), [accessed July 2014]): plant height, Nfixation, woodiness and evergreeness. Plant height was an ordinal variable with the following categories: 1 : $<0.5 \mathrm{~m} ; 2: 0.5$ to $1 \mathrm{~m} ; 3: 1$ to $3 \mathrm{~m} ; 4: 3$ to $5 \mathrm{~m} ; 5:>5 \mathrm{~m}$. Tall plants are expected to invest more in C-rich support tissues than short plants, which may have consequences in the $\mathrm{C} / \mathrm{N}$ of the soil (Cornelissen et al. 1996). Moreover, taller plants tend to send roots deeper into the soil (Canadell \& Zedler 1995) and have the potential to uplift water from deep to shallow soil layers (Peñuelas \& Filella 2003), leading to higher surface soil moisture during the dry months. N-fixation ability (binomial variable: yes/no) determines the ability of plants to incorporate atmospheric $N$ into their tissues and then to the soil (Fustec et al. 2010). Woodiness (binomial variable: yes/no, depending on whether the stem is partly/totally lignified or not) was selected as a proxy for the speed of the nutrient cycles. Lignin, which is an important component of wood, is a recalcitrant compound which bonds with proteins haltering the activity of decomposing microorganisms (Gallardo \& Merino 1993). Under equal abiotic conditions, communities dominated by woody plants are expected to have higher soil $\mathrm{C} / \mathrm{N}$ and less soil decomposing activity than communities dominated by non-woody plants. Finally, evergreeness (binomial variable: photosynthetic organs present all year-round or not) was selected because long-lasting photosynthetic organs should have a higher proportion of defense and support compounds to the detriment of productive tissues (Herms \& Mattson 1992), leading to slower decomposition (Cornelissen et al. 1999) and to less available $N$ in the soil. Moreover, evergreen canopies would contribute to a shading of the soil, reducing evaporation and preserving soil moisture during the dry season.

\section{Indexes of functional structure}

For each island we obtained a species $\mathrm{x}$ trait matrix and a species $\mathrm{x}$ abundance matrix to calculate functional structure indexes. CWMs were assessed for each plot and trait by multiplying the trait value of each species (0/1 for binomial traits and 1-4 for plant height) by the species frequency in the plot and summing up this product across all species present in the plot. Functional diversity indexes (FRic, FEve, FDiv, FDis), as well as species richness, were assessed for each plot on each island. FRic, as the amount of functional space filled by a community, was calculated as the minimum convex hull in a 4-dimentional space (one dimension per trait) which includes all the species of a plot (Villeger et al. 2008). FEve accounts for both the regularity of spacing between species along the minimum spanning tree (i.e. the 
tree that links all the species contained in the trait space) and the evenness in the distribution of abundance across species (Villeger et al. 2008). FDiv represents how abundance is spread through the trait space; it requires first calculating the center of gravity among the species forming the vertices of the convex hull containing all species, and then summing up the abundance-weighed distance of every species to the center of gravity (Villeger et al. 2008). FDis is the abundance-weighed mean distance of individual species to the centroid of all species in the trait space (Laliberte \& Legendre 2010). All indexes were calculated using the FD package of R (Laliberte \& Legendre 2010). Finally, we put forward an index of FRedu based in the proportion between the number of species with different combinations of trait values (singular species) and the total number of species. It was calculated as:

$$
\text { FRedu }=1-\frac{\text { number of singular species }}{\text { number of species }} \text { (equation 1) }
$$

where the number of singular species is the number of unique combinations of trait values among the species. This index equals zero when all species have a different combination of trait values, and increases in magnitude when the number of species increases faster than the number of singular species (i.e. when many species show the same combination of trait values). The relationship between FRedu and each index of functional diversity was tested with the Spearman correlation coefficient, as FRedu did not follow a normal distribution.

To disentangle the effects of the invader's presence and those of the change in the resident species composition, the above indexes were calculated in the invaded plots both including and excluding Carpobrotus. Each index of functional structure was compared between noninvaded and invaded plots - with and without Carpobrotus- by means of independent paired $t$ test or Wilcoxon-test for non-normal variables. Mallorca and Menorca paired plots were analyzed separately.

\section{Relationships between functional diversity indexes and ecosystem properties}

We performed general linear models to assess if there was a relationship between each ecosystem property (response variable) and each functional index (explicative variable), accounting for the effects of invasion status (invaded and non-invaded), island (Mallorca and Menorca) and the interaction term "functional index $x$ invasion status" as fixed factors. The interaction term allowed us to check whether the relation varied between invaded and noninvaded communities. When this interaction was not significant, we repeated the analysis excluding it to increase the degrees of freedom. When necessary, we applied log- or squared root transformations to the response variables to increase homocedasticity and normality of model residuals. All analyses were performed using $\mathrm{R}$ version 3.2.1.

\section{Results}

\section{Changes in the functional structure of the community}

Given the dominance of Carpobrotus in the invaded plots, its invasion dragged CWM values to make them closer to Carpobrotus trait values. Carpobrotus height was similar to that of most species in the native community and thus CWM of plant height did not change with invasion. Carpobrotus is woody and evergreen, traits that are not very common in the native community. Therefore, CWM of woodiness and evergreeness were higher in the Carpobrotusinvaded plots. Carpobrotus is not $\mathrm{N}$ fixing, so the invaded plots have a lower CWM for Nfixation (Table 1, Fig. 1). By contrast, when Carpobrotus was excluded from CWM calculations, the invaded plots showed lower CWM for the four traits, except evergreeness in Menorca (Appendix S1, S2), suggesting that the invader mostly displace tall, woody, N-fixing and evergreen native plants.

Consistently in the two islands, species richness notably declined in the invaded plots (Table 1). Three out of the four diversity indexes explored (FRic, FDiv and FDis) also tended to 
decline in invaded plots, though differences in Menorca were not significant (FRic) or only marginally significant (FDiv and FDis). FRedu was lower in the invaded plots in the two islands (Table 1). These trends stood when Carpobrotus was excluded from index calculations (Appendix S1).

FRedu significantly increased with species richness and decreased with FEeve, but was unrelated to FRic, FDiv and FDis (Appendix S3).

Table 1. Comparison of functional indexes. Paired t-test comparison of functional structure indexes between paired plots invaded and non-invaded by Carpobrotus spp. in Mallorca and Menorca. Carpobrotus was included to calculate indexes of invaded plots.

\begin{tabular}{lllllll}
\hline & \multicolumn{3}{c}{ MALLORCA } & & & MENORCA \\
\hline Indexes $^{(1)}$ & invaded & non-invaded & $P^{(2)}$ & invaded & non-invaded & $P^{(2)}$ \\
\hline CWM $_{\mathrm{ph}}$ & $1.26 \pm 0.07$ & $1.37 \pm 0.09$ & ns & $1.22 \pm 0.05$ & $1.30 \pm 0.05$ & $\mathrm{~ns}$ \\
CWM $_{\text {wd }}$ & $0.56 \pm 0.05$ & $0.30 \pm 0.04$ & $* *$ & $0.43 \pm 0.05$ & $0.28 \pm 0.05$ & $* * *$ \\
CMW $_{\mathrm{Nf}}$ & $0.06 \pm 0.02$ & $0.13 \pm 0.02$ & $* *$ & $0.07 \pm 0.02$ & $0.11 \pm 0.03$ & $\dagger$ \\
CWM $_{\mathrm{eg}}$ & $0.83 \pm 0.03$ & $0.67 \pm 0.05$ & $* *$ & $0.73 \pm 0.06$ & $0.52 \pm 0.05$ & $* *$ \\
SpRic & $7.76 \pm 1.23$ & $13.29 \pm 1.42$ & $* * *$ & $11.36 \pm 1.24$ & $16.57 \pm 1.01$ & $* * *$ \\
FRic & $3.23 \pm 0.71$ & $6.29 \pm 0.61$ & $* *$ & $4.87 \pm 1.07$ & $5.85 \pm 1.09$ & $\mathrm{~ns}$ \\
FEve & $0.44 \pm 0.04$ & $0.39 \pm 0.03$ & $\mathrm{~ns}$ & $0.33 \pm 0.03$ & $0.32 \pm 0.03$ & $\mathrm{~ns}$ \\
FDiv & $0.70 \pm 0.03$ & $0.79 \pm 0.02$ & $* *$ & $0.72 \pm 0.03$ & $0.79 \pm 0.03$ & $\dagger$ \\
FDis & $1.39 \pm 0.11$ & $1.67 \pm 0.06$ & $*$ & $1.49 \pm 0.07$ & $1.69 \pm 0.08$ & $\dagger$ \\
FRedu & $0.30 \pm 0.05$ & $0.45 \pm 0.04$ & $*$ & $0.46 \pm 0.06$ & $0.58 \pm 0.03$ & $*$ \\
\hline
\end{tabular}

(1) SpRic- species richness, FRic- Functional richness, FEve- Functional evenness, FDiv- Functional divergence, FDisFunctional dispersion, FRedu- Functional redundancy, CWM- Community weighed means for plant height (ph), woodiness (wd), $\mathrm{N}$-fixation (Nf) and evergreeness (eg).

(2) P-values: *** $P \leq 0.001 ; * * 0.01 \geq P>0.001 ; * 0.05 \geq P>0.01 ;+0.1 \geq P>0.05 ;$ ns $P>0.1$. Asterisks in italics indicate that the non-parametric Wicoxon test for paired samples was performed because data did not fulfill normality.

\section{Relationships between functional structure and ecosystem properties}

Our analyses revealed little effect of Carpobrotus invasion on the assessed ecosystem properties, as only soil organic carbon showed a slight trend to be higher in invaded sites (Appendix S4). Menorca plots showed less organic $\mathrm{C}$ and $\mathrm{C} / \mathrm{N}$ than Mallorca plots and they also showed a slight trend to have less soil moisture in the dry season (Appendix S4). Overall, the relationship between functional structure indexes and ecosystem properties was weak, yet some relevant patterns emerged: FRic was negatively associated to soil organic $C$, but only across invaded plots (Fig 2A, Appendix S4); FEve was positively related to soil moisture in the dry season (Fig. 2B); FRedu was positively related to soil $\mathrm{C} / \mathrm{N}$ and negatively to total soil $\mathrm{N}$ (only in invaded plots) and to soil moisture in the dry season (Fig. 2C, D, E, Appendix S4). Contrary to our expectation of stronger relationship in non-invaded plots, the invasion status only affected two relationships: FRic-soil organic C and FRedu-soil total $\mathrm{N}$ (Appendix S4), and in both, the relation was stronger in the invaded sites (Fig 2A, C). 

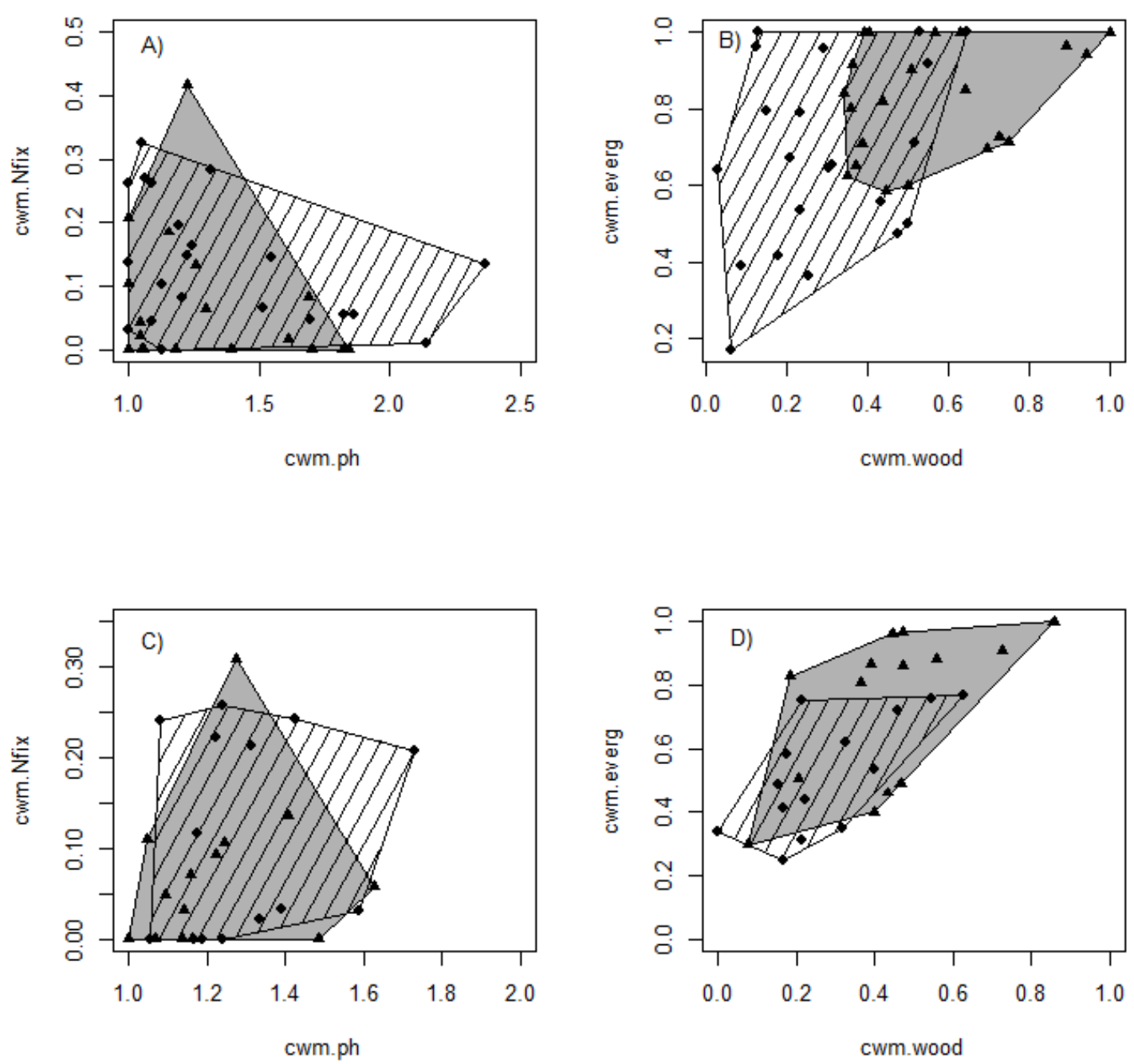

Figure 1. Functional spaces occupied by communities. Dotcharts showing the position of Carpobrotus invaded (triangles) and non-invaded plots (diamonds) in the space defined by the community weighed means (CWM) of plant height and $\mathrm{N}$-fixation $(\mathrm{A}, \mathrm{C})$ and by the CWMs of woodiness and evergreenes ( $\mathrm{B}$, D). A, B- Mallorca, C, D - Menorca. CWMs of invaded plots were calculated including Carpobrotus. The grey and lined areas include all invaded and non-invaded plots, respectively. 

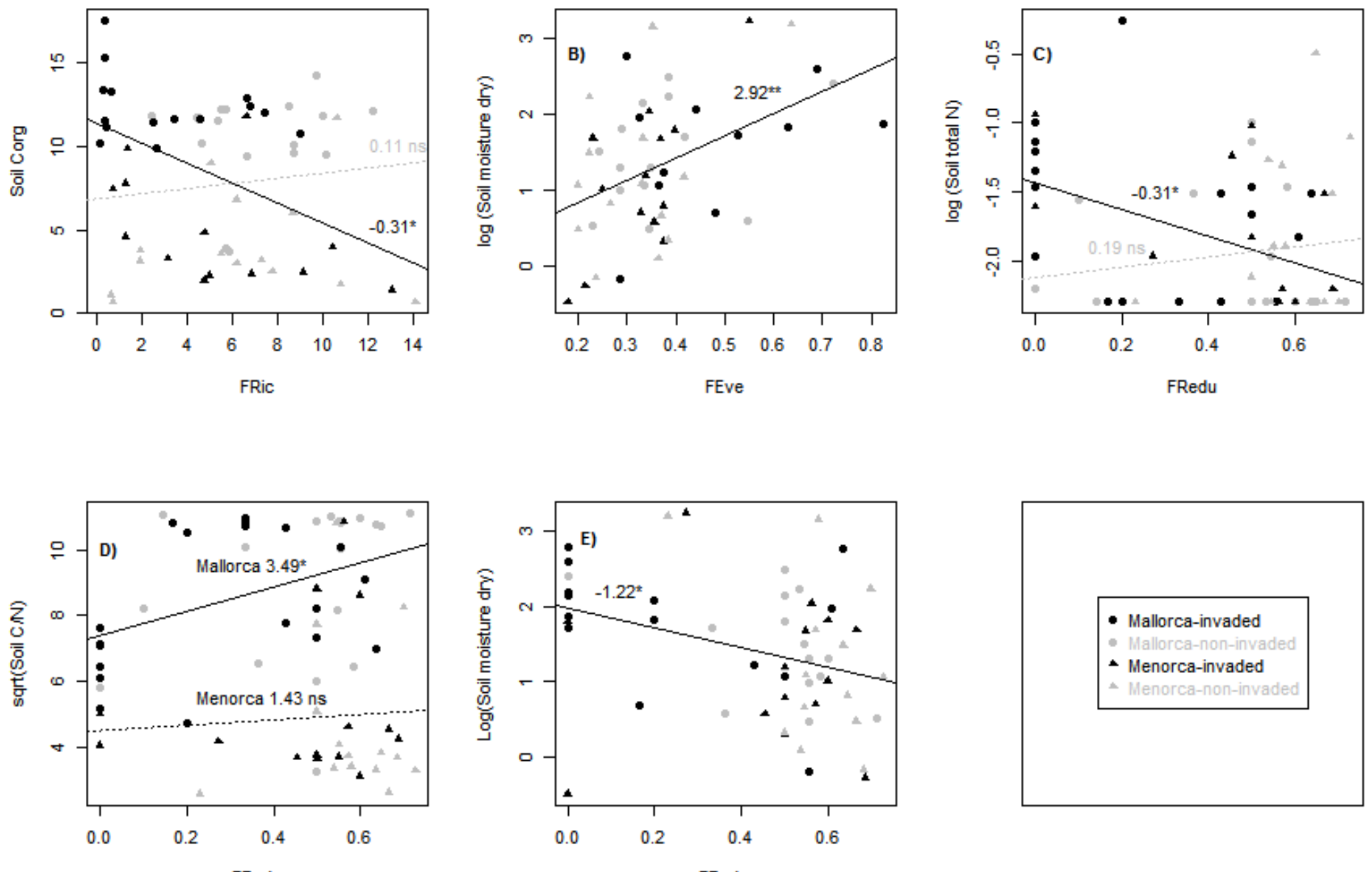

Figure 2. Relationship between functional indexes and ecosystem properties. Lines show the adjustment between variables and the coefficient of the functional index in a linear model with the ecosystem property as dependent variable and the functional property, island and invaded status as fix factors (all coefficients are shown in Table 2). Two lines are shown in the same graph when there was a significant interaction between the functional index and invaded status (black and grey lines for invaded and noninvaded plots respectively) or between the functional index and the island. Significance: ${ }^{* * *} p \leq 0.001,{ }^{* *} 0.01 \geq p>0.001,{ }^{*} 0.05 \geq p>0.01,+0.1 \geq p>0.05, n s p>0.01$. 


\section{Discussion}

\section{Effects of invasion on functional structure}

Most of the analyzed indexes of functional structure were altered with Carpobrotus invasion. These changes were both related to the local loss of native species and to the introduction of a dominant species, which differs in some trait values from those prevailing in the non-invaded community. The higher frequency of woodiness and evergreeness in the invaded plots was due to the high dominance of the invader, which is woody and evergreen, as the native species remaining in the invaded plots showed lower frequency of both traits than those of the noninvaded plots. By contrast, the lower frequency of $\mathrm{N}$-fixation in the invaded plots is explained both by the fact that Carpobrotus is not $\mathrm{N}$-fixing and by the lower frequency of $\mathrm{N}$-fixation among the native species remaining in the invaded plots. These changes might slow down nutrient cycles, because woody and evergreen plants generally produce less decomposable litter than herbs and deciduous plants (Gallardo \& Merino 1992; Cornelissen et al. 1999; Castro-Díez et al. 2009), and might decrease soil $\mathrm{N}$ because of the lower frequency of $\mathrm{N}$-fixers (Hooper \& Vitousek 1998; Levine et al. 2003). However, our results failed to show relations between CWMs and ecosystem properties, as discussed below.

Plots invaded by Carpobrotus showed a notable reduction of species, as stated before (Vilà et al. 2006). This species loss was accompanied by reductions in parameters describing functional diversity (FRic, FDiv and FDis in Mallorca and the two latter in Menorca). While FRic often depends on the number of species, FDiv and FDis are independent of species richness (Villeger et al. 2008; Laliberte \& Legendre 2010). The lower FDiv and FDis values in invaded plots -either when Carpobrotus was included and excluded- indicates that species are less dispersed in the functional space (FDiv) and are closer to the centroid defined by all species traits (FDis) than in non-invaded communities. Carpobrotus invasion reduced the frequency of tall, woody, $\mathrm{N}$-fixing and evergreen native plants (see Appendix S1). This means that the native species more negatively affected were similar to Carpobrotus for woodiness and evergreness, but different for plant height and $\mathrm{N}$-fixation. This result partly agrees with predictions by two alternative hypotheses: the biotic-resistance hypothesis states that competition is the main filter for species establishment and predicts higher extinction risk for native species functionally closer to a successful invader (Fargione et al. 2003; Tecco et al. 2010). By contrast, the environmental filtering hypothesis states that abiotic stress or disturbance are the main filters for species and predicts higher extinction risk for native species ecologically more distant to an invader capable of modifying the micro-environment (Tecco et al. 2010; Lapiedra et al. 2015). Therefore, our results suggest that both competition and environmental filtering equally contribute to structure the studied community.

The low functional diversity of the invaded communities reveals a within-community functional homogenization. Biotic homogenization is a frequent outcome of biological invasions (Olden et al. 2004; Lososová et al. 2015), but it has been more often explored from a phylogenetic than from a functional perspective (Lapiedra et al. 2015; Lososová et al. 2015). While the ecological and evolutionary consequences of a phylogenetic homogenization are not straightforward (Olden et al. 2004), a decrease in the functional diversity has been related to reduced overall ecosystem resource-use efficiency (Tilman et al. 1997) and resistance/resilience to environmental change, because of the decline in the range of species specific responses (Olden et al. 2004; Oliver et al. 2015). Accordingly, Dukes (2002) found lower resistance to species invasions in grasslands with low functional diversity. However, this did not happen when soil fertility was the main driver of species success (Harrison et al. 2015).

In both islands, the species loss was accompanied by a decline of FRedu. Less functionally redundant communities might be more susceptible to lose relevant functions by 
environmental changes, because they have a smaller pool of species available to compensate for local extinctions (Olden et al. 2004; Oliver et al. 2015).

Although the concepts of redundancy and diversity are somehow opposed, we only found a negative correlation between FRedu and one index of functional diversity, i.e. evenness. This is not surprising given that an assemblage with species more evenly distributed through the functional space has fewer chances to have functionally redundant species. Given that FRedu is easy to assess, has clear ecological implications and was highly sensitive to Carpobrotus invasion, we suggest that it can be used to interpret the functional consequences of invasions.

\section{Relationships between functional structure and ecosystem properties}

The analyzed ecosystem properties were less sensitive to Carpobrotus invasion than the functional properties of the community, as only soil organic $\mathrm{C}$ was higher in the invaded sites. This effect had been previously reported and attributed to the high litter production by the invader (Vilà et al. 2006). Previous studies have also found a strong impact of invaders on community structure, but a non-consistent impact on soil properties and mineralization rates (Vilà et al. 2006; Castro-Díez et al. 2009). This suggests that there is a time lag between the change in community structure and changes in soil properties, most probably because the soil organic matter accumulated before the invasion remains for some time controlling soil processes (Berendse et al. 1989; Castro-Díez et al. 2009). Such a time lag may also contribute to explain the weak association found between the functional indexes and ecosystem properties. In fact, several studies have shown that the relation between changes in plant traits and soil properties becomes stronger with time (Strayer et al. 2006; Castro-Díez et al. 2009). Unfortunately, we lack information on invasion times to test this hypothesis. In addition, other local factors, such as disturbances or micro-environmental heterogeneity, may contribute to distort the expected relations. Finally, the selected traits -mostly binomial- may be less sensitive to show links with ecosystem properties than other related quantitative traits (e.g. specific leaf mass or leaf $\mathrm{N}$ content). In spite of these limitations, our results still show several associations which may be used to predict the trajectory of the ecosystem properties in the future.

In invaded plots, FRic was negatively associated to soil organic $C$. This may be explained by a faster mineralization of organic matter when litter with contrasted properties is mixed up (De Marco et al. 2011). Additionally, this pattern may simply reflect the above-mentioned positive association between Carpobrotus and soil organic C. According to the complementary niche hypothesis, we expected communities with higher functional diversity to exploit resources more efficiently and thus reduce soil resource availability. However, FEve was the only functional diversity index related to soil moisture and the correlation was positive instead. Contrary to expectations, more functionally redundant communities were associated with lower soil $\mathrm{N}$ (only across invaded sites) and lower soil moisture in the dry season. Our results suggest a higher depletion of soil resources by more intense resource uptake from the same soil layer when several species share similar combinations of trait values.

Contrary to our hypothesis, the association between functional indexes and ecosystem properties was not stronger in non-invaded sites. This suggests that non-invaded ecosystems are not closer to an equilibrium between biotic and abiotic properties than invaded ones. Rather, they may have experienced other disturbances (e.g. trampling, browsing) that have broken such an equilibrium in a similar way as an invasion.

\section{Conclusions}

Our study highlights that the use of functional structure indexes may provide much deeper insights on the impacts of plant invasions on native communities than the classical analysis of species richness or diversity. Moreover, by using plant "effect traits" to characterize plant 
species, changes in the functional structure of the community may be linked to changes in the ecosystem processes. The invasion of coastal rocks, cliffs and sand dunes by Carpobrotus in Mallorca and Menorca changed the spectra of community functional traits towards a higher frequency of woody and evergreen species and a lower frequency of $\mathrm{N}$-fixers. Carpobrotus invasion not only reduces species richness of the recipient communities but also their functional diversity and redundancy, which can affect their resilience. Contrary to our expectations, these changes of functional structure were scarcely paralleled by changes in ecosystem properties, probably because the latter responded to the invasion at a slower rate than the former.

\section{Acknowledgments}

This study was supported by the projects CGL2015-65346-R and CGL2011-16388/BOS of the Ministerio de Economía y Competitividad of Spain and POII10-0179-4700 of the Junta de Comunidades de Castilla-La Mancha. Field sampling was founded by the 5th EU Framework project EPIDEMIE (Contract no. EVK2-CT-2000-00074). PCD acknowledges CONICYT (Ministry of Education, Chile Government) for granting her stay at Concepción University ("Concurso de atracción de Capital Humano Extranjero-MEC" program) and support of the REMEDINAL3-CM MAE-2719 network (Comunidad de Madrid). AP was partially funded by the Institute of Ecology and Biodiversity with the grants by the Ministry of the Economy ICM P05-002, and CONICYT PFB-23. AT acknowledges support from the LINCGLOBAL project between CSIC (Spain) and U. Católica de Chile. MV acknowledges support through the Severo Ochoa Program for Centers of Excellence in R+D+l (SEV-2012-0262).

Devesa, J.A., Quintanar, A. \& García, M.Á. (eds.) 2015. Flora iberica XVI(I). 734 pp. Real Jardín Botánico, CSIC, Madrid.

\section{Literature}

Berendse, F., Bobbink, R. \& Rouwenhorst, G. 1989. A comparative-study on nutrient cycling in wet heathland ecosystems. 2. Litter decomposition and nutrient mineralization. Oecologia 78: 338-348.

Butterfield, B.J. \& Suding, K.N. 2013. Single-trait functional indices outperform multi-trait indices in linking environmental gradients and ecosystem services in a complex landscape. Journal of Ecology 101: 9-17.

Cadotte, M.W., Carscadden, K. \& Mirotchnick, N. 2011. Beyond species: functional diversity and the maintenance of ecological processes and services. Journal of Applied Ecology 48: 1079-1087.

Canadell, J. \& Zedler, P.H. 1995. Underground structures of woody plants in Mediterranean ecosystems of Australia, California, and Chile. In: Arroyo, M.T.K., Zedler, P.H. \& Fox, M.D. (eds.) Ecology and Biogeography of Mediterranean ecosystems in Chile, California, and Australia, pp. 177-210. Springer-Verlag, New York.

Casanoves, F., Pla, L., Di Rienzo, J.A. \& Diaz, S. 2011. FDiversity: a software package for the integrated analysis of functional diversity. Methods in Ecology and Evolution 2: 233237.

Castro-Díez, P., Godoy, O., Alonso, A., Gallardo, A. \& Saldaña, A. 2014. What explains variation in the impacts of exotic plant invasions on the nitrogen cycle? A meta-analysis. Ecology Letters 17: 1-12.

Castro-Díez, P., González-Muñoz, N., Alonso, A., Gallardo, A. \& Poorter, L. 2009. Effects of exotic invasive trees on nitrogen cycling: a case study in Central Spain. Biological Invasions 11: 1973-1986. 
Constan-Nava, S., Soliveres, S., Torices, R., Serra, L. \& Bonet, A. 2015. Direct and indirect effects of invasion by the alien tree Ailanthus altissima on riparian plant communities and ecosystem multifunctionality. Biological Invasions 17: 1095-1108.

Cornelissen, J.H.C., Castro-Díez, P. \& Hunt, R. 1996. Seedling growth, allocation and leaf attributres in a wide range of woody plant species. Journal of Ecology 84: 755-765.

Cornelissen, J.H.C., Pérez-Harguindeguy, N., Díaz, S., Grime, J.P., Marzano, B., Cabido, M., Vendramini, F. \& Cerabolini, B. 1999. Leaf structure and defense control litter decomposition rate across species and life forms in regional floras on two continents. The New Phytologist 143: 191-200.

Chapin, F.S., Reynolds, H., D'Antonio, C.M. \& Eckhart, V. 1996. The functional role of species in terrestrial ecosystems. In: Walker, B. \& Steffen, W. (eds.) Global Change in Terrestrial Ecosystems, pp. 403-428. Cambridge University Press.

Chapin, F.S., Walker, B.H., Hobbs, R.J., Hooper, D.U., Lawton, J.H., Sala, O.E. \& Tilman, D. 1997. Biotic control over the functioning of ecosystems. Science 277: 500-504.

D'Antonio, C.M. \& Corbin, J.D. 2003. Effects of plant invaders on nutrient cycling: Using models to explore the link between invasion and development of species effects. In: Canham, C.D., Cole, J.J. \& Lauenroth, W.K. (eds.) Models in Ecosystem Science, pp. 363-384. Princeton University Press, Princeton (NJ).

De Marco, A., Meola, A., Maisto, G., Giordano, M. \& De Santo, A.V. 2011. Non-additive effects of litter mixtures on decomposition of leaf litters in a Mediterranean maquis. Plant and Soil 344: 305-317.

Díaz, S. \& Cabido, M. 2001. Vive la difference: plant functional diversity matters to ecosystem processes. Trends in Ecology \& Evolution 16: 646-655.

Dukes, J.S. 2002. Species composition and diversity affect grassland susceptibility and response to invasion. Ecological Applications 12: 602-617.

Fargione, J., Brown, C.S. \& Tilman, D. 2003. Community assembly and invasion: An experimental test of neutral versus niche processes. Proceedings of the National Academy of Sciences of the United States of America 100: 8916-8920.

Filella, I. \& Peñuelas, J. 2003. Partitioning of water and nitrogen in co-occurring Mediterranean woody shrub species of different evolutionary history. Oecologia 137: 51-61.

Finegan, B., Pena-Claros, M., de Oliveira, A., Ascarrunz, N., Bret-Harte, M.S., CarrenoRocabado, G., Casanoves, F., Diaz, S., Velepucha, P.E., (...) \& Poorter, L. 2015. Does functional trait diversity predict above-ground biomass and productivity of tropical forests? Testing three alternative hypotheses. Journal of Ecology 103: 191-201.

Fustec, J., Lesuffleur, F., Mahieu, S. \& Cliquet, J.B. 2010. Nitrogen rhizodeposition of legumes. A review. Agronomy for Sustainable Development 30: 57-66.

Gaertner, M., Den Breeyen, A., Hui, C. \& Richardson, D.M. 2009. Impacts of alien plant invasions on species richness in Mediterranean-type ecosystems: a meta-analysis. Progress in Physical Geography 33: 319-338.

Gallardo, A. \& Merino, J. 1993. Leaf decomposition in two Mediterranean ecosystems of southwest Spain: influence of substrate quality. Ecology 74: 152-161.

Gallardo, A. \& Merino, J. 1992. Nitrogen inmobilization in leaf litter at two Mediterranean ecosystems of SW Spain. Biogeochemistry 15: 213-228.

Garnier, E., Cortez, J., Billes, G., Navas, M.L., Roumet, C., Debussche, M., Laurent, G., Blanchard, A., Aubry, D., (...) \& Toussaint, J.P. 2004. Plant functional markers capture ecosystem properties during secondary succession. Ecology 85: 2630-2637.

Grime, J.P. 1998. Benefits of plant diversity to ecosystems: immediate, filter and founder effects. Journal of Ecology 86: 902-910.

Harrison, S., Cornell, H. \& Grace, J.B. 2015. Does natural variation in diversity affect biotic resistance? Journal of Ecology 103: 1099-1106.

Hejda, M. \& de Bello, F. 2013. Impact of plant invasions on functional diversity in the vegetation of Central Europe. Journal of Vegetation Science 24: 890-897. 
Hejda, M., Pyšek, P. \& Jarosik, V. 2009. Impact of invasive plants on the species richness, diversity and composition of invaded communities. Journal of Ecology 97: 393-403.

Herms, D.A. \& Mattson, W.J. 1992. The dilemma of plants: to grow or defend. Quaterly Review of Biology 67: 283-335.

Hooper, D.U., Chapin, F.S., Ewel, J.J., Hector, A., Inchausti, P., Lavorel, S., Lawton, J.H., Lodge, D.M., Loreau, M., (...) \& Wardle, D.A. 2005. Effects of biodiversity on ecosystem functioning: A consensus of current knowledge. Ecological Monographs 75: 3-35.

Hooper, D.U. \& Vitousek, P.M. 1997. The effects of plant composition and diversity on ecosystem processes. Science 277: 1302-1305.

Hooper, D.U. \& Vitousek, P.M. 1998. Effects of plant composition and diversity on nutrient cycling. Ecological Monographs 68: 121-149.

Kumschick, S., Gaertner, M., Vilà, M., Essl, F., Jeschke, J.M., Pyšek, P., Ricciardi, A., Bacher, S., Blackburn, T.M., (...) \& Winter, M. 2015. Ecological impacts of alien species: quantification, scope, caveats, and recommendations. BioScience 65: 55-63.

Laliberte, E. \& Legendre, P. 2010. A distance-based framework for measuring functional diversity from multiple traits. Ecology 91: 299-305.

Lapiedra, O., Sol, D., Traveset, A. \& Vilà, M. 2015. Random processes and phylogenetic loss caused by plant invasions. Global Ecology and Biogeography 24: 774-785.

Lavorel, S. \& Garnier, E. 2002. Predicting changes in community composition and ecosystem functioning from plant traits: revisiting the Holy Grail. Functional Ecology 16: 545-556.

Levine, J.M., Vilà, M., D'Antonio, C.M., Dukes, J.S., Grigulis, K. \& Lavorel, S. 2003. Mechanisms underlying the impacts of exotic plant invasions. Proceedings of the Royal Society of London Series B-Biological Sciences 270: 775-781.

Lososová, Z., de Bello, F., Chytrý, M., Kühn, I., Pyšek, P., Sádlo, J., Winter, M. \& Zelený, D. 2015. Alien plants invade more phylogenetically clustered community types and cause even stronger clustering. Global Ecology and Biogeography 24: 786-794.

Mouillot, D., Graham, N.A.J., Villéger, S., Mason, N.W.H. \& Bellwood, D.R. 2013. A functional approach reveals community responses to disturbances. Trends in Ecology \& Evolution 28: 167-177.

Olden, J.D., Poff, N.L., Douglas, M.R., Douglas, M.E. \& Fausch, K.D. 2004. Ecological and evolutionary consequences of biotic homogenization. Trends in Ecology \& Evolution 19: $18-24$.

Oliver, T.H., Heard, M.S., Isaac, N.J.B., Roy, D.B., Procter, D., Eigenbrod, F., Freckleton, R., Hector, A., Orme, C.D.L., (...) \& Bullock, J.M. 2015. Biodiversity and Resilience of Ecosystem Functions. Trends in Ecology \& Evolution 30: 673-684.

Peñuelas, J. \& Filella, I. 2003. Deuterium labelling of roots provides evidence of deep water access and hydraulic lift by Pinus nigra in a Mediterranean forest of NE Spain. Environmental and Experimental Botany 49: 201-208.

Petchey, O.L. \& Gaston, K.J. 2006. Functional diversity: back to basics and looking forward. Ecology Letters 9: 741-758.

Pyšek, P., Jarosik, V., Hulme, P.E., Pergl, J., Hejda, M., Schaffner, U. \& Vilá, M. 2012. A global assessment of invasive plant impacts on resident species, communities and ecosystems: the interaction of impact measures, invading species' traits and environment. Global Change Biology 18: 1725-1737.

Richardson, D.M., Pyšek, P., Rejmánek, M., Barbour, M.G., Panetta, F.D. \& West, C.J. 2000. Naturalization and invasion of alien plants: concepts and definitions. Diversity and Distributions 6: 93-107.

Roiloa, S.R., Rodriguez-Echeverria, S., de la Pena, E. \& Freitas, H. 2010. Physiological integration increases the survival and growth of the clonal invader Carpobrotus edulis. Biological Invasions 12: 1815-1823. 
Sintes, T., Moragues, E., Traveset, A. \& Rita, J. 2007. Clonal growth dynamics of the invasive Carpobrotus affine acinaciformis in Mediterranean coastal systems: A non-linear model. Ecological Modelling 206: 110-118.

Strayer, D.L., Eviner, V.T., Jeschke, J.M. \& Pace, M.L. 2006. Understanding the long-term effects of species invasions. Trends in Ecology \& Evolution 21: 645-651.

Tecco, P.A., Diaz, S., Cabido, M. \& Urcelay, C. 2010. Functional traits of alien plants across contrasting climatic and land-use regimes: do aliens join the locals or try harder than them? Journal of Ecology 98: 17-27.

Thuiller, W., Gallien, L., Boulangeat, I., de Bello, F., Munkemuller, T., Roquet, C. \& Lavergne, S. 2010. Resolving Darwin's naturalization conundrum: a quest for evidence. Diversity and Distributions 16: 461-475.

Tilman, D., Knops, J., Wedin, D., Reich, P., Ritchie, M. \& Siemann, E. 1997. The influence of functional diversity and composition on ecosystem processes. Science 277: 1300-1302.

Traveset, A., Brundu, G., Carta, L., Mprezetou, I., Lambdon, P., Manca, M., Médail, F., Moragues, E., Rodríguez-Pérez, J., (...) \& Hulme, P.E. 2008a. Consistent performance of invasive plant species within and among islands of the Mediterranean basin. Biological Invasions 10: 847-858.

Traveset, A., Moragues, E. \& Valladares, F. 2008b. Spreading of the invasive Carpobrotus aff. acinaciformis in Mediterranean ecosystems: The advantage of performing in different light environments. Applied Vegetation Science 11: 45-54.

Vilà, M., Espinar, J.L., Hejda, M., Hulme, P.E., Jarosik, V., Maron, J.L., Pergl, J., Schaffner, U., Sun, Y. \& Pyšek, P. 2011. Ecological impacts of invasive alien plants: a meta-analysis of their effects on species, communities and ecosystems. Ecology Letters 14: 702-708.

Vilà, M., Rohr, R.P., Espinar, J.L., Hulme, P.E., Pergl, J., Le Roux, J.J., Schaffner, U. \& Pyšek, P. 2015. Explaining the variation in impacts of non-native plants on local-scale species richness: the role of phylogenetic relatedness. Global Ecology and Biogeography 24: 139-146.

Vilà, M., Tessier, M., Suehs, C.M., Brundu, G., Carta, L., Galanidis, A., Lambdon, P., Manca, M., Médails, F., (...) \& Hulme, P.E. 2006. Local and regional assessment of the impacts of plant invaders on vegetation structure and soil properties of Mediterranean islands. Journal of Biogeography 33: 853-861

Villeger, S., Mason, N.W.H. \& Mouillot, D. 2008. New multidimensional functional diversity indices for a multifaceted framework in functional ecology. Ecology 89: 2290-2301.

Violle, C., Navas, M.L., Vile, D., Kazakou, E., Fortunel, C., Hummel, I. \& Garnier, E. 2007. Let the concept of trait be functional! Oikos 116: 882-892.

\section{Supporting information}

Appendix S1. Comparison of functional indexes with Carpobrotus excluded.

Appendix S2. Functional spaces occupied by communities with Carpobrotus excluded.

Appendix S3. Relationship between functional redundancy (FRedu) and other indexes of functional structure

Appendix S4. Effects of community structure indexes on ecosystem properties 